\title{
La asimilación del eidos platónico en la estética schopenhaueriana
}

\section{The assimilation of Platonic eidos in Schopenhauer's aesthetics}

\author{
JOSÉ ANTONIO CABRERA RODRÍGUEZ \\ Universidad de Sevilla
}

Recibido: 14/06/2017

Aceptado: 19/12/2017

\begin{abstract}
RESUMEN
En el presente estudio se indaga cómo asimila Schopenhauer la noción de eidos platónico en su discurso estético. Partiendo de su teoría sobre la representación y entendiendo la idea como un grado de objetivación de la voluntad metafísica, se expondrá hasta qué punto es una intuición eidética la que legitima las artes (a excepción de la música). Veremos así que, gracias a este importante concepto platónico, Schopenhauer consigue elucidar, desde una perspectiva tan metafísica como gnoseológica, la experiencia estética y la obra artística.
\end{abstract}

PALABRAS CLAVE

IDEA PLATÓNICA (EIDOS), ARTE, VOLUNTAD, CONTEMPLACIÓN, CATARSIS.

ABSTRACT
In this research, we investigate how Schopenhauer assimilates the notion of Platonic eidos in his aesthetical discourse. By starting from his theory of representation and understanding idea as a degree of objectification of the metaphysical will, we will explain how an eidetic intuition legitimates arts (except for music). Thanks to this important Platonic concept, we will see that Schopenhauer manages to elucidate aesthetic experience and artistic work metaphysical as well as gnoseollogically.

$$
\begin{gathered}
\text { KEYWORDS } \\
\text { PLATONIC IDEA (EIDOS), ART, WILL, CONTEMPLATION, CATHARSIS. }
\end{gathered}
$$

(C) Contrastes. Revista Internacional de Filosofia, vol. XXII-N² (2017), pp. 175-191. ISSN: 1136-4076 


\section{I.INTRODUCCIÓN.}

ME GUSTARÍA CONSIDERAR en el presente estudio un tema que me parece muy significativo en relación con una jornada dedicada al legado del pensamiento griego en la filosofía alemana. Es este un tema que, anclando de raíz en la doctrina platónica, alcanza, a poco que sorprenda por los veintitrés siglos de distancia, las puertas mismas de la filosofía contemporánea: las puertas abiertas por Arthur Schopenhauer. En efecto, ¿qué mejor legado para un pensador tan influyente como controvertido que el concepto fundamentalmente platónico de eidos? ¿Y qué mayor reto a los efectos sino reabrir el diálogo entre Platón y Schopenhauer a propósito de lo que aquél conculcaba como espurio conocimiento, a saber, el plano de la experiencia estética a través del arte?

En esta comunicación vamos a centrarnos, pues, en analizar cómo asimila e interpreta precisamente Schopenhauer el concepto de eidos platónico, que constituye un imponderable soportal de su discurso estético. Para ello, convendrá ante todo escudriñar someramente a qué empeño obedece dicho discurso y por qué cobra el eidos su peculiar calado no ya para la adquisición de una episteme o conocimiento verdadero en sentido científico, como quería Platón, sino como condición legitimadora de la experiencia estética contemplativa que nos brinda el artista.

\section{LA NATURALEZA DEL EIDOS.}

\section{II.1. EL EIDOS COMO REPRESENTACIÓN SUPRAEMPÍRICA.}

Si bien en la doctrina de la representación empírica con la que estrena su magna obra El mundo como voluntad y representación, Schopenhauer iba tras las huellas kantianas, bajo ninguna circunstancia la experiencia sensible agota la faz representacional del mundo, como sí que ocurría en el criticismo kantiano. Lo que Schopenhauer llama «representación» no debe inducirnos de inmediato a considerarla únicamente enlazada con el fenómeno kantiano, pues hay experiencias que, aunque plasmadas en éste, no engarzan sin más con él, sino que se abren también a realidades no limitadas por el principium individuationis. Este es justamente el caso del eidos platónico, la mediación transtemporal e inespacial más clarividente y perfecta en que la voluntad puede manifestarse. Es por ello por lo que Schopenhauer recurre al maestro por antonomasia de la tradición filosófica occidental, aquel que concedió a la Idea el estatuto ontológico máximo según el cual se la situaba más allá de todo tiempo y espacio, encarnación absoluta de la eternidad y la incorruptibilidad, de la identidad perfecta consigo misma sin huecos que valgan para el no ser o el movimiento que al mundo físico es consustancial. El eidos es lo nunca nacido (ingénito) y lo nunca mortal (imperecedero), lo que nunca pasa de moda, lo que se resiste al 
avance o al retroceso, al «aquí» o al «allá». Independiente en grado extremo de todo sujeto, a nada es relativo ni puede ser agotado desde perspectiva alguna; está clausurado en sí mismo, prodigándonos un inagotable venero ontológico de perfección, del que cada individuo bebe cual caduco y trivial ejemplo suyo de entre los infinitos que podrían advenir a nuestra mudadiza realidad.

No obstante, ya de primeras podemos advertir que un punto de discrepancia entre la noción platónica de eidos y la que reinterpreta Schopenhauer estriba en la idea de participación (mézexis). Leyendo more platónico, con eidos o Idea designamos la realidad auténticamente real (léase verdadera), última e inapelable en que se agota todo el ser (siendo su entidad máxima la Idea eterna

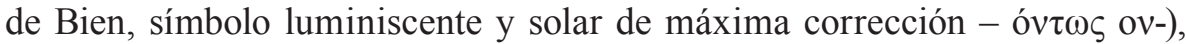
y que imitarían (mímesis) con sus imperfecciones los múltiples ejemplares desperdigados por este mundo material, sobre el que nuestros sentidos nos informan dándonos variables opiniones. Con Schopenhauer, sin embargo, la realidad ultimísima, lo que Kant había llamado «cosa en sí», no se identifica exactamente con la Idea, sino con la voluntad; sólo que ahora la Idea, más que entablar una relación participativa con ella, la objetiva inmediatamente en un grado pleno y excelso para el sujeto que la contempla. ${ }^{1}$

Sea como fuere, Schopenhauer equipara las ideas platónicas a los diversos grados de objetivación de la voluntad ${ }^{2}$ (desde las fuerzas naturales más básicas y universales -gravedad, impenetrabilidad, rigidez...- hasta las formas orgánicas más especializadas y superiores -la vida humana-), intuitivamente aprehendidos por las diversas artes. Rosset ha observado a este respecto:

«La idea schopenhaueriana designa mucho más que la forma general de la representación de la voluntad en la conciencia. El uso que de ella hace Schopenhauer sugiere una definición más precisa; no es la representación de la voluntad en general, sino la representación de un gran orden de hechos de la voluntad (...) La idea schopenhaueriana es la intuición de un modelo general de fuerzas». ${ }^{3}$

Adviértase aquí además otra consecuencia no menos importante. Dado que Schopenhauer inserta el eidos dentro del orbe representacional, se plantea

1 Es significativo que Schopenhauer acepte ideas, y no una Idea única, seguramente porque así le resulte más fácil clasificar jerárquicamente las dignidades ontológicas (desde la materia inorgánica hasta la orgánica), así como distribuir las distintas ideas entre las diversas artes existentes por su época. Como concluiremos, el problema con que chocaría es el haber introducido la pluralidad en su teoría de las ideas, como bien objetara Magee, puesto que al hacerlo estaría admitiendo implícitamente como presupuesto explicativo el principio de individuación (que justamente es lo que pretende anular en la experiencia contemplativa).

2 A. Schopenhauer, El mundo como voluntad y representación. Madrid: Trotta, 2004, p. 182.

3 C. Rosset, Écrits sur Schopenhauer. París: PUF, 1969, pp. 35-36. 
un problema de complicada solución: ¿subsistiría la Idea fuera de la experiencia estética en que el genio o sujeto artístico la contempla, es decir, depende en su aparecer objetual del contemplador, o guardaría algún tipo de independencia fuera de la experiencia estética? Desde luego que para Platón la Idea nada le debía a la mente finita que la pensara, siendo autosuficiente e independiente de toda otra realidad (una mismidad absoluta), pero Schopenhauer no lo tiene tan claro como el ateniense:

«la idea platónica es necesariamente objeto, algo conocido, una representación; y precisamente por eso, aunque solo por eso, distinta de la cosa en sí. Se ha despojado únicamente de las formas subordinadas del fenómeno que concebimos juntas bajo el principio de razón, o, más bien, no ha llegado a ingresar en ellas; pero ha mantenido la forma primera y más universal, la de la representación en general: la de ser objeto para un sujeto». ${ }^{4}$

A nuestro juicio, apostaremos por religar la Idea a la representación supraempírica, juzgándola un modo de traslucirse la voluntad a una subjetividad que descansa del trasiego ordinario en que su esencia consiste, elevándose sobre su propia individualidad, sobre las formas tempoespaciales y causales que determinan su entorno fenoménico, para fundirse con ella en una aprehensión especial, extrarracional y propiamente estética donde desaparece la conciencia actual de grieta sujeto-objeto. En este sentido, el eidos no es autosuficiente ni absoluto en sí mismo, sino relativo a una subjetividad pura, una subjetividad descontaminada de las limitadoras estructuras fenoménicas y no urgida ya por intereses ni deseos cotidianos, logrando así una serenidad y una dicha que aleja el sufrimiento y amargor de esa vida que llevamos en cuanto individuos desgarrados de la unidad primordial. Con el eidos el sujeto se libera por unos instantes del poderío de la voluntad sintiendo en sus adentros, frente a la frialdad de un mundo inhóspito, el transmundano calor de la felicidad. ${ }^{5}$

Debemos prevenirnos por tanto de embrollar el concepto de cosa en sí con el concepto de eidos. Consabido es que la cosa en sí kantiana, el noúmeno, corresponde para Schopenhauer a la voluntad, de manera que el eidos no se circunscribirá más que a objetivar con la mayor perfección posible la cosa en sí irracional. El porqué de que Schopenhauer introduzca un intermediario entre el mundo de Maya y la cosa en sí ofrece no pocos quebraderos de cabeza, sobre todo si tenemos presente que admite una forma de manifestación directa y sin intermediaciones para la voluntad, cuya función le competería desempeñar a

4 A. Schopenhauer, op. cit., p. 229.

5 Marín Torres ha advertido bien que el llamado «goce estético» no debe confundirse con el placer suscitado por las afecciones volitivas; nuestra fruición ante la belleza nos nace no por haber satisfecho una necesidad, por una saciedad; «al contrario, este sentimiento se asemeja más a una paz celestial o calma absoluta, resultante de la carencia de toda necesidad». J. M. Marín Torres, Agnosticismo y estética. Estudios schopenhauerianos. Valencia: Nau Libres, 1986, p. 82. 
la música. Ciertamente se necesita justificar el plano empírico desde aquella cosa en sí. Sin embargo, ¿por qué no se podría hacer lo propio con un supuesto plano eidético? De hecho, podríamos acogernos muy bien a un nominalismo que prescindiera del eidos o de universales metafísicos y no precisaríamos justificar nada que rebasara los objetos percibidos en nuestra experiencia sensible. Sin embargo, Schopenhauer diserta largo y tendido sobre las ideas sin aportar nunca un argumento que justifique la necesidad de estas intermediaciones entre los fenómenos y la cosa en sí. ${ }^{6}$ Quizás el único modo de justificarla obedezca sencillamente a fines estéticos -algo que bien iremos analizando-, o lo que vale decir: quizás el eidos constituya un ingrediente fundamental para perfilar desde el ámbito artístico una teoría del conocimiento que acaso logre resolver el problema de la validez objetiva en el arte, distanciándose a este respecto de las concepciones expresionistas y románticas que defendían a capa y espada la ineludible existencia de un sujeto libre y creador. ${ }^{7}$

\section{II.2. IDEA Y CONCEPTO.}

La invención del kosmos noetós no fue oriunda del platonismo. Según declara Schopenhauer, «la teoría de las ideas procede originariamente de Pitágoras, si no queremos desconfiar de la información de Plutarco en el libro de De placitis philosophorum I, $2 »{ }^{8}$ Pero en cualquier caso, aun inspirado por Pitágoras, Platón delineó y asentó definitivamente el idealismo metafísico en la cultura occidental. Un sistema idealista como el suyo tiene por principio que

6 En este sentido comparto la perplejidad manifiesta por Magee ante el hecho de que Schopenhauer duplique el plano representacional: «No veo ninguna razón por la que los argumentos de Schopenhauer acerca de que las artes representativas nos proporcionan un tipo especial de conocimiento de las Ideas Platónicas, que son manifestaciones directas del nóumeno, no puedan transferirse, mutans mutandis, a la teoría de que las artes representativas nos dan un tipo especial de conocimiento del mundo empírico que es una manifestación directa del nóumeno». B. Magee, Schopenhauer. Madrid: Cátedra, 1991, p. 260.

7 Así podría tener razón Mann pronunciando lo siguiente: «Al suponer o comprobar una jerarquía y una graduación en la multiplicidad de las objetivaciones de la voluntad, conquistó o salvó las «Ideas», pues éstas eran precisamente esa graduación, puramente intuida, de las emanaciones de la voluntad. Las cosas individuales no eran una objetividad del todo adecuada de la voluntad, sino una objetividad enturbiada por las formas de nuestro conocimiento. En verdad nosotros no conoceríamos, según Schopenhauer, «ejemplares», acontecimientos, no conoceríamos ningún cambio, ninguna multiplicidad, sino que conoceríamos tan sólo lo que es, conoceríamos tan sólo la objetividad inmediata y pura de la voluntad en sus diversos grados. Y nuestro mundo sería, por tanto, para hablar con los escolásticos, un nunc stans, un «ahora permanente» de Ideas límpidas y eternas». T. Mann, Schopenhauer, Nietzsche, Freud. Madrid: Alianza Editorial, 2000, pp. 30-31.

8 A. Schopenhauer, El mundo como voluntad y representación, II (Complementos). Madrid: Trotta, 2004, p. 412. 
la realidad auténticamente subsistente y absoluta, independiente del tiempo, del sujeto y la materia, son las Ideas.

Por eidos podemos entender también sin temor a equivocarnos lo que Aristóteles entendiera por especie (species), esto es, un arquetipo universal y general bajo el que se subsumirían los entes individuales que comparten entre sí un mismo modus essendi o forma de ser, unas características comunes a todos estos. Pero aquí vuelve a resultar problemática la definición, por cuanto entraría en colisión directa con el concepto abstracto, el universal, que Schopenhauer sí aborda desde un prisma nominalista, al considerarlo un producto de la facultad abstractiva que opera sobre la experiencia particular y cuyo uso compete no más que al científico. Si por un lado afirma que la voluntad de vivir hace prevalecer la especie sobre los individuos, y que por tanto se objetiva directamente en ella cuando contemplamos las Ideas, ¿qué diferencia real existiría entre el concepto de árbol, de cuyo conocimiento se ocuparía el científico, y la Idea de árbol, la arboreidad, sólo intuible por el artista genial? A menos que salvaguardemos la Idea en un plano ontológico y convirtamos el concepto en un instrumento exclusivo de la humana facultad dialéctica, la ambivalencia y confusión estarán más que servidas. Pero aceptar el primer supuesto supondría desviar el eidos de su trayectoria representacional en cuanto objeto perfecto que objetiva directamente la voluntad, lo que en tal caso le obligaría a inmiscuirse en el terreno nouménico reservado exclusivamente para ésta. Schopenhauer se halla aquí tan acorralado como lo estuviera Descartes con su controvertida glándula pineal (la actual epífisis, cuya anatomía ya estudió por vez primera Andrés Vesalio en su De Humani Corporis Fabrica de 1543), que no era ni completamente física y ni completamente espiritual: la Idea parece gozar de un estatuto ontológico a la par que gnoseológico. Y sobre todo cuando, como ya apuntamos antes, sólo a la música le corresponde objetivar por derecho, sin ninguna mediación que la vehicule, la cosa en sí original.

Sea como fuere, concepto e Idea no deben ser equiparados entre sí; por más que designen un tipo de entidad universal, ambos varían su significado según le convenga o no el principio de razón. Por eso sentencia Schopenhauer:

«La idea es la unidad disgregada en la pluralidad en virtud de la forma espacio-temporal de nuestra aprehensión intuitiva: en cambio, el concepto es la unidad restablecida desde la pluralidad a través de la abstracción de nuestra razón: se la puede designar como unitas post rem y aquella como unitas ante rem». ${ }^{9}$

La Idea es, pues, la perfecta unidad objetiva entregada a nuestra intuición, que

9 A. Schopenhauer, El mundo como voluntad y representación, op. cit., p. 289. El encarnizado debate de los universales protagonizado a partir del siglo XII giraba en torno a esta cuestión de si los universales gozaban de una realidad independiente, more platonico, como 
por dirigirse hacia la belleza es estética, y por tener el eidos como correlato inmediato, es eidética. De ahí que sólo sea en un conocimiento contemplativo - además del conocimiento puro y transeidético de la música- donde reside el valor de la auténtica obra artística. Si por el concepto la intuición es fructificada y abstraída de sus adhesiones materiales, posibilitando la reflexión, por la Idea platónica la intuición adopta el rango de contemplación. Así, con la arboreidad Schopenhauer ejemplifica:

«Cuando, por ejemplo, contemplo un árbol estéticamente, es decir, con ojos de artista, de modo que no lo conozco a él sino su idea, inmediatamente carece de significado si se trata de este árbol o de un antepasado suyo que floreció hace miles de años, como también si el observador es este o cualquier otro individuo que vive en cualquier tiempo y lugar»». ${ }^{10}$

\section{LA ANÁMNESIS EIDÉTICA Y SU EFECTO CATÁRTICO.}

En cuanto a la relación entre contemplación y purificación corpórea, sin embargo, Schopenhauer se acerca claramente a Platón. Tanto en los textos de Fedón como en el Fedro, el filósofo ateniense mantenía una postura muy contundente con nuestro envoltorio somático: al encarnarnos en él, nuestra alma olvida las Formas puras que había contemplado en su existencia prematerial. Desde una perspectiva netamente epistemológica, pues, la teoría de la anamnesis eidética, cuyo núcleo narraba Platón en el Fedro, exigía dar por sentado que el cuerpo nos introduce en un estado amnésico del que sólo podríamos librarnos practicando la vita contemplativa (paralela a la vita activa), lo cual llevaba consigo como ganancia una virtud imposible de conquistar por vía exclusivamente sensorial. Por eso la anámnesis de las entidades más puras, ${ }^{11}$ como recuerdo de lo que nuestra alma ya conocía en una vida sin ataduras somáticas, nace de un impulso erótico (eros, orexis), filosófico, para el que no todo el mundo está capacitado; pues la mayoría tantea entre tinieblas vagando por un mundo aparente en que confunde la belleza en sí con la belleza para sí, o la justicia en sí con la justicia que él, como cada cual, juzga verdadera,

pretende Guillermo de Champeaux; o si no son más que el fruto de elaboraciones racionales, entre cuyas filas militaban los bandos conceptualista y nominalista.

10 ibid., p. 264.

11 En la anamnesis eidética se palpa muy bien el significado etimológico de lo que aquí estamos exponiendo: pues, habida cuenta del prefijo privativo griego «a» y el étimo «amnesia» (olvido), ¿qué designaría ella, sino un «des-olvido»-al que añado el adjetivo «eidético», siendo lo «des-olvidado» las propias Ideas? 
en una obvia filiación apologética con el relativismo axiológico defendido por sofistas como Protágoras o Pródico de Ceos. ${ }^{12}$

Gracias a esta remembranza sabemos que nuestra realidad aparente participa de un kosmos ouranós perfecto, y que participa igual que lo hace la copia (Nachbild) respecto del original (Vorbild). ${ }^{13}$ Así pues, Schopenhauer bien pudiera revalidar esta postura en la medida que la intuición eidética (contemplatio) va asociada al olvido momentáneo del cuerpo, que es lo que a fin de cuentas presupone un intelecto emancipado, en su mirar, de la voluntad. Si el cuerpo expresa directamente esta voluntad en cada uno de nosotros, y al contemplar nos olvidamos de él, lo estamos purificando de los deseos mundanales a los que aquella lo empuja; estamos conduciéndolo hacia una libertadora catarsis. Platón ya nos avisaba de que una vida invertida en buscar la verdad, condición de la vida virtuosa (por herencia del intelectualismo socrático), era una vida que bien merecía la pena vivir, y que tendría su inmejorable gratificación en que nuestra alma escaparía por fin tras la muerte de esta ergástula somática que la aprisiona. Aun cuando estemos encarnados, podemos anticipar con nuestros nobles actos especulativos la depuración absoluta de todas las necesidades corpóreas, escapando, como bien planteaban también los hindúes, de un ciclo de metempsicosis o reencarnaciones que no podría otorgarnos nunca la felicidad completa. Es la purificación parcial y transitoria del cuerpo mediante la actividad contemplativa lo que Schopenhauer, siguiendo a Platón, piensa que podría otorgarnos al menos un atisbo de esa felicidad tan plena. Como muy bien ha apuntado Janaway, lo que Schopenhauer llama «conciencia mejor» (besseres Bewusstsein) determina este tomar conciencia de que nuestra voluntad queda acrisolada cuando hace oídos sordos a todos los reclamos somáticos: «la libertad de la «conciencia mejor» que Schopenhauer asocia al cese de la voluntad se asemeja a la «purificación» de los deseos y otros obstáculos (...)».14

\section{Del «VELo DE MAYA» AL «VELo DE LAS MUSAS».}

El estado contemplativo, en su grado más insigne, «es el estado indoloro que Epicuro celebró como el supremo bien y el estado de los dioses: pues por aquel instante nos hemos desembarazado de aquel vil afán de la voluntad, celebramos el sabbath de los trabajos forzados del querer y la rueda de Ixión se detiene». ${ }^{15}$ Efectivamente, la intuición eidética nos brinda un descanso sabático

12 Cfr. VV. AA., Sofistas, testimonios y fragmentos. Madrid: Gredos, 1996.

13 A. Schopenhauer, op. cit., p. 223.

14 C. Janaway, «Knowledge and tranquility: Schopenhauer on the value of art», en J. Dale (ed.), Schopenhauer, Philosophy, and the Arts. Cambridge: Cambridge University Press, 1996, p. 46.

15 A. Schopenhauer, El mundo como voluntad y representación, op. cit., p. 250. 
del trajín al que nos empujan las cargas cotidianas, y por ello la intuición intelectiva que entraña la contemplación nos entrega algo tan divino como el eidos. La contemplación en que se sustenta la intuición eidética se asemeja por tanto, como bien dice Schopenhauer citando a Epicuro, a la visio deorum, que aquí entroncaría con la visión de lo divino platónico, procurándonos un alivio sin par al anestesiarnos de los dolores del mundo. Hegel, más cristianizante por su parte, había dicho que con el arte festejamos los «domingos de la vida» frente a los días normales de trabajo; un trabajo que Marx habría condenado como la fuente de alienación de la sociedad y el despótico pretexto para que unos vivan a cuerpo de rey mientras otros sufren sangre, sudor y lágrimas, incitando por ello a la liberación de la esclavitud por medio de una vía muy distinta a la que nos brinda la contemplación estética, a saber: la revolución práxica.

Al visitar el orbe del arte, descorremos un velo para correr otro: rasgamos el velo de Maya para descubrir el maravilloso velo de las musas. Ante los fenómenos vemos con una claridad menor que la desprendida por el eidos, aunque no obstante estemos bajo el fulgor de una nueva llama, por más que ella no ilumine tanto como el sol. Todo en el mundo del conocimiento está vinculado con el símbolo de la luz y la claridad, ya sea bajo el primer velo o bajo el segundo. La realidad genuina y absolutamente real, lo que para Platón se correspondía con la idea, para Schopenhauer queda confiscado por la voluntad. Y la voluntad, por propia definición, es un no ser (pleno), una pura carestía, un querer al que le falta algo, un impulso (Trieb) que precisa llenar para escapar de su vacío. Como el non finito miguelangelesco, la voluntad es también lo in-finito, lo perpetuamente inacabado. La cosa en sí, la realidad verdadera que en Platón era justamente eidética, se torna en Schopenhauer universo de la noche, de la umbría y de la nada. Dentro de la oscura caverna reside la verdad, y no fuera: la realidad es lo eternamente ausente a la lúcida conciencia, lo que conlleva inmediatamente una lucidez de lo no lúcido. Lo que llamamos ser sólo se iguala al fenómeno, al aparecer: la verdad metafísica y existencial del mundo es para nosotros un no ser, una fisura en el reino del ser como aparecer. Y así, mientras que el sol nos engaña cegándonos con cósicas o eidéticas objetividades, entre las sombras intuimos la presencia de lo ausente, el origen desgarrado (por cuanto escindido) y desgarrador (por cuanto pungente) del mundo como representación. Nadie antes que Schopenhauer había alcanzado con tanta pujanza semejante planteamiento alusivo a la carencia y el desear como trasfondo ontológico de cuanto se nos presenta ante nuestros sentidos o bajo el sol de la beldad.

Por pertenecer a un mundo gobernado por el principio de razón, plagado de seres corruptibles y plurales, nuestra visión temporal ha de ser menesterosamente parcial y limitada, pero tiene como referencia las Ideas absolutas, que 
como nulidad del tiempo trasluce una eternidad sobrehumana. En palabras de Schopenhauer:

«El tiempo es solamente la visión fragmentaria y disgregada que tiene un ser individual de las ideas, las cuales están fuera del tiempo y son, por lo tanto, eternas: por eso dice Platón que el tiempo es la imagen movida de la eternidad:

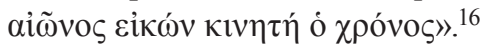

Y esta «imagen movida de la eternidad» que es el tiempo lo vivenciamos colectivamente como historicidad, algo de lo que ya dieron muy buena cuenta filósofos de la talla de Vico, Hegel, Marx, Dilthey, Croce, von Ranke o el propio Ortega y Gasset, pues todo cuanto acaece a la especie humana puede ser narrado por la razón histórica, contrapartida de la razón vital y biográfica que sirve para contarnos la historia de nuestra vida. Contemplando las ideas nos sustraemos al decurso histórico, y con ello nuestra mirada se vuelve inextricablemente transhistórica; así lo ilustra Schopenhauer citando la sutilísima frase pronunciada por Schiller: «lo que nunca y en ninguna parte ha sucedido / solo eso no envejece nunca». ${ }^{17}$ Nuestra historia, así pues, vindica también in abstracto el efecto cronológico que ejerce en la comunidad humana el velo de Maya, pero como para intuir una idea tenemos forzosamente que rasgarlo, su división en aconteceres diversos, contingentes y fechables se disuelve tan pronto como logremos una experiencia estética; los eventos históricos quedan atrapados in saecula saeculorum entre las mallas del velo de Maya, siendo tan «accidental e indiferente a la idea misma como a las nubes las figuras que representan, al arroyo sus remolinos y figuras espumosas, y al hielo sus árboles y flores». ${ }^{18}$ Frente a la división fenoménica del acaecer histórico, nos sale al encuentro la unidad indivisa del eidos; frente a intuiciones parcializadas y secuenciadas como en un filme de los hechos personales (biografías) o grupales (historia), la contemplatio nos permite intuir eternidades; ${ }^{19}$ sólo por y para ellas

16 ibid., p. 230.

17 [Schiller, «A los amigos», 49] cit. por A. Schopenhauer, op. cit., p. 302.

18 ibid., p. 237.

$19 \mathrm{Al}$ hilo de este intuir eternidades viene a colación el texto borgiano Historia de la eternidad, espléndido por su calidad literaria y filosófica disertando sobre, entre otros temas, las ideas platónicas como primer gran ontificación en Occidente de lo eterno -bastante pareja a la posición con la que Heidegger, bien que con otras intenciones especulativas mucho más asépticas, ejemplifica en Ser y tiempo el gran olvido del ser que supuso el idealismo metafísico platónico (el ser dinámico cristalizado en la idea estática)-. Borges conecta el deseo humano hacia lo que no existe (ínfula transhistórica), hacia posibilidades no realizadas o futuribles, precisamente con la eternidad, llevando a término este entramado eidético que Schopenhauer probablemente debió de inspirarle: «El hombre enternecido y desterrado que rememora posibilidades felices, las ve 
podrá despertarse en nuestro ánimo el formidable sentimiento de lo bello y lo sublime, cuyas ideas irrigan el ámbito de la contemplación estética.

\section{LA CONTEMPLACIÓN EIDÉTICA COMO FUNDAMENTO LEGITIMADOR DEL ARTE.}

Para Schopenhauer, es el genio quien encarna la persona habilitada para la intuición eidética; la genialidad tiende su lazo hacia el kosmos noetós, cuyos estratos, divididos según los grados de objetivación de la voluntad metafísica, presenta el genio en sus múltiples facetas. No hablaremos propiamente de un genio in abstracto, sino de los genios, pues habrá tantos y tan variados como las artes fundadas conforme a las variadas Ideas. Así pues, el sujeto puro del conocer personificado por la figura del genio contempla las Ideas según un escalafón que denota los grados de visibilidad en que se objetiva la voluntad primordial. La experiencia artística, en cuanto actividad contemplativa y realizativa de dichas ideas, comprende un escalafón análogo de artes según el grado de objetivación que corresponda: las ideas de gravidez e impenetrabilidad en la arquitectura, la de la belleza y la gracia en la escultura, la de humanidad en la poesía, etc. Porque el artista comunica en sus obras las mismas ideas distribuidas en la scala naturae, desde los organismos más bajos e inertes (minerales) hasta los más altos e inteligentes (humanos).

El especialista en la estética schopenhaueriana André Fauconnet ha interpretado que la manera como Schopenhauer clasifica todas las artes obedece, entre algunos otros, a un criterio muy discreto: lo que él denomina «ley de contrastes» (loi de contraste): «resulta que, puesto que todas las artes tienen como fin el facilitarnos la clara intuición de las ideas que constituyen los grados de la objetividad de la voluntad, todas ellas deben manifestar el desacuerdo de las tendencias, la lucha de las fuerzas contrarias»». ${ }^{20}$

Sin la aprehensión eidética que intuitivamente alcanza el artista, no se podría hablar con propiedad de creación artística; acaso sólo nos sea dable hablar de simple artesanía. En análogo sentido, Simmel declara lo siguiente:

«la obra de arte existe por su contenido — es decir, la idea —, y todo lo que podría llamarse lo funcional del arte, el estilo, la aplicación de los medios técnicos, la expresión de la individualidad artística, la solución del problema propio exclusivamente de cada arte, sólo recibe su interés del interés de la idea que forma el contenido de la obra de arte». ${ }^{21}$

sub specie aeternitatis, con olvido total de que la ejecución de una de ellas excluía o postergaba las otras». J. L. Borges, Historia de la eternidad. Madrid: Alianza, 1981, p. 38.

20 A. Fauconnet, L'esthethique de Schopenhauer. París: Felix Alcan, 1913, p. 73.

21 G. Simmel, Schopenhauer y Nietzsche. Barcelona: Francico Beltrán, 1915, p. 105. 
Hay que destacar también que el sentimiento que brota en el espectador cuando contempla la Idea puede resultar variable, en función de si prepondera lo objetivo (la concepción de la Idea) o lo subjetivo (la beatitud y serenidad concomitantes); y ello a su vez según cuál sea la Idea subrepticia en cada objeto intuido. Dicho por Schopenhauer:

«la fuente del placer estético unas veces radicará más en la captación de la idea conocida y otras en la felicidad y tranquilidad de espíritu del conocimiento puro liberado de todo querer y, con ello, de toda individualidad y del tormento que de ella deriva: y ese predominio de uno u otro componente del placer estético dependerá de si la idea captada intuitivamente constituye un grado superior o inferior de la objetividad de la voluntad».22

Con la intuición estética eidética, el conocimiento ha subido palpablemente de categoría, abandonando su amarre en el terreno empírico. Más aún: el conocimiento que preside la intuición eidética necesaria para el artista no debería ser denominado propiamente «conocimiento», atinente más bien a una importante función biológica desarrollada por los organismos con sistema nervioso central. Por esta razón, la actividad contemplativa nos suministra no ya un conocimiento sin más relacionado con la voluntad, sino la ansiada sabiduría; pues mientras que el científico o el hombre corriente se halla entretenido con las apariencias sensibles, que se empeña en salvar, el contemplador, donde tiene su sede la subjetividad trascendental, mira hacia la esencia dejando muy atrás esas apariencias. Pues, en efecto, ser sabio consiste en conocer sin ningún interés particular, sino por el puro placer de conocer. Por ello asevera Schopenhauer:

«Tal captación de lo universal en el individuo que se represente en cada caso coincide también con lo que he llamado el puro sujeto involuntario del conocimiento y establecido como el correlato subjetivo de la idea platónica; porque el conocimiento solamente puede permanecer involuntario cuando está dirigido a lo universal; en cambio, en las cosas individuales se hallan los objetos del querer».23

El sabio es quien conoce inútilmente porque conoce al margen del querer. Y este es, en definitiva, un conocimiento de la esencia, de lo universal: cuando el sujeto pierde su individualidad para intuir lo universal, se purifica haciéndose uno con su objeto, hasta el punto de que en la contemplación estética se difuminan todas las fronteras separativas entre sujeto y objeto, lo mismo que cuando contemplamos extasiados un paisaje, olvidamos que hay una persona contemplándolo; el sujeto se ha vuelto, por así decir, él mismo el paisaje. La conversión del sujeto empírico en sujeto puro del conocimiento pasa entonces por la metamorfosis de un sujeto con voliciones en un sujeto avolitivo que ha

22 A. Schopenhauer, op. cit., pp. 250-251.

23 A. Schopenhauer, Parerga y paralipómena. Madrid: Trotta, 2007, p. 34. 
dejado de querer para únicamente conocer por conocer, que es en lo que radica la sabiduría estética propia del artista. Así lo ha expresado también muy lúcida y concisamente Ávila Crespo:

«Cuando el individuo se olvida de sus intereses particulares, cuando es capaz de prescindir de la urgencia de la necesidad, puede entonces entregarse a la intuición contemplativa y estética, entonces deja de ser individuo y se convierte en puro sujeto del conocer, más allá de la voluntad, de la pasión y del tiempo». ${ }^{24}$

Adquirir la sabiduría estética queda exclusivamente reservado para el genio, ya que no cualquiera llega tan lejos como para ser sabio. Como podremos recordar, tal postura no hace sino reivindicar la que ya existía desde los pensadores griegos, especialmente Platón y Aristóteles. Para Platón concretamente, lo máximo a lo que desde luego podrían aspirar por mayoría los mortales sería a seguir errabundos como en la archifamosa alegoría que narraba en $L a$ República, donde unos esclavos presos en el interior de una caverna sombría cometían errores por confundir lo real con lo aparente, sin saber que hay un mundo exterior fuera de la caverna en la que creen haber morado toda su vida. Sólo quien se hubiera soltado de los grilletes y se encaminara hacia la salida iría descubriendo poco a poco la verdad, hasta que, una vez al aire libre, alzara con dificultad su rostro hacia el sol que baña con su fúlgida luz todas las cosas haciéndolas visibles, tomándolo por el principio de visibilidad de todo lo que se nos pone ante nuestra vista. Luego vendría la ardua tarea de comunicar tan monumental hallazgo a quienes lo ignorasen, pero evidentemente la reacción del nesciente no se haría esperar: reputaría de insano y trastornado a quien con tanto entusiasmo fuera predicando esa «buena nueva». Y así, lejos de ser creído, se granjearía la incredulidad de casi todos ellos, e incluso el más ruin ludibrio, como apunta Schopenhauer. ${ }^{25}$ Pues bien, a su peculiar manera, el genio artístico bien podría intentar comunicar a los demás su experiencia sin precedentes, pero a duras penas conseguiría ningún resultado convincente, como mucho las resonantes carcajadas de tan ramplonas gargantas. Con todo y con eso, nadie podrá negarle su capacidad para alcanzar una experiencia única y predilecta, una intuición especial que le reporta un gozo incomparable con el que puedan experimentar los hombres de a pie, los individuos con espíritu filisteo, regodeados con sus frívolos placeres. Según Remedios Ávila:

24 R. Ávila Crespo, «Metafísica y arte. El problema de la intuición en Schopenhauer», en VV. AA., Anales del seminario de metafísica XIX. Madrid: Ed. Universidad Complutense, 1984, p. 161.

25 A. Schopenhauer, El mundo como voluntad y representación, op. cit., p. 245. 
«(...) mediante la intuición estética, el hombre se convierte en un testigo mudo del mundo, en un visionario de esencias, cuya función será ahora transmitir a otros lo que 'vio' en un momento en que su voluntad no empañaba los contornos ni el contenido de la visión, en un instante en que lo visto era el mundo, y no su voluntad proyectada en el mundo». ${ }^{26}$

El arte, por tanto, como instancia mediadora entre el intelecto y el universo eidético, entraña el linimento de la angustia y desazón del sujeto volente en el mundo representacional. El arte es un amable aquietador de la voluntad interesada en danzar incansablemente por el salón de los fenómenos, un portador de placer y de verdad eidética desde el altozano donde se aposta un sujeto puro invicto por haber burlado los corsés de la pluralidad (Vielheit): espacio, tiempo y causalidad. ¿La recompensa? Penetrar una realidad allende el fenómeno, inespacial e intemporal, ajena al juego de encadenamientos causales, sin ser causa de nada ni efecto de nada, sino más bien emanación u objetivación adecuada de la voluntad misma: en suma, la theorein que abraza el eidos ahora y siempre, en todo lugar y en ninguno, sin más porqués ni para qués que el extasiarse contemplando los inmarcesibles prototipos inmateriales de las cosas, las imágenes inmóviles que proyectaran lo que Platón bautizase como «eternidad inmóvil».

Pero hay que dejar aquí constancia de que la voluntad en ningún caso es extirpada durante el acto contemplativo estético, sino sólo aplacada, pacificada, subyugada. Lo contrario supondría un contrasentido: para inteligir Ideas hace falta ser antes intelecto, y no podemos olvidar que el ser emerge siempre desde la voluntad. Quizás muestre cierta imprecisión Thomas Mann aseverando que «durante ese dominio del intelecto, la voluntad, eliminada y desposeída de su poder, sucumbe de modo suave y dichoso». ${ }^{27}$ La voluntad sigue estando presente, continúa obrando en nosotros (jamás sucumbe ni queda eliminada), pero lo hace de una forma tan leve que no empaña la transparencia, claridad y puridad que la contemplatio le demanda al sujeto. El arte nos dispensa olvido de una realidad que en nuestros adentros somos hasta que nos despertamos de la sublime ensoñación y volvemos a faenar con las fatigas del diario vivir: es entonces cuando recobra sus fuerzas la voluntad, despierta de su letargo y reclama su derecho soberano sobre la súbdita inteligencia: no hay placer que cien años dure. Sea como fuere, siempre quedará el arte para hacer mutis a la onerosa carga de la rutina.

26 R. Ávila Crespo, op. cit., p. 163.

27 T. Mann, op. cit., p. 38. 
Distinto es, empero, reconocer cierta infrecuencia en la sensibilidad estética de quienes practican la actividad contemplativa, esto es, los genios y artistas, un rango que está reservado a unos pocos (bien pudiéramos hablar aquí de una oligarquía de artistas). Desde luego, aquí sí que tendría más sentido utilizar el calificativo de «milagroso» para adjetivar la experiencia estética que propone Schopenhauer, pudiendo coincidir con Mann cuando resalta a Schopenhauer como un teórico de las «bendiciones del arte». ${ }^{28}$

Sintetizando, el arte se vuelve aquí acreedor del mayor grado cognoscitivo que se haya conocido hasta la fecha en ningún sistema especulativo, contra la preceptiva platónica consistente en preterirlo a un burdo intento mimético de la physis, cuya función en la arena política dañaría más que favorecería la educación del ciudadano, aturullándolo con ficciones y mentiras que lo distanciarían de la deseable episteme hacia la que debe encaminar sus pasos el hombre virtuoso.

\section{CONCLUSIÓN}

Así pues, y llegados a este punto, comprobamos lo mucho que el sistema schopenhaueriano tiene de grecogermano, al adeudar no sólo a Kant, sino sobre todo a Platón - sin mencionar a estoicos y cirenaicos para algunos de sus consejos eudemonológicos-, gran parte de sus mayores inspiraciones. Quien más y quien menos podrá, pues, reconocer tras todo lo argüido que, si rebuscamos entre las raíces filosóficas que nutren la estética de Schopenhauer, daremos frente por frente con Platón como directo inspirador de su teoría sobre las bellas artes, si bien dejara a muy buen resguardo la música como arte superior y aislado, precisamente inafectado por la contemplación eidética.

Es bastante interesante advertir cómo según Schopenhauer el eidos, que constituye ante todo lo que denomina un grado de objetivación del sustrato último, la voluntad metafísica, convierte la experiencia estética en un asunto preeminentemente gnoseológico. Por ello se ve comprometido el concepto mismo de verdad manejado por el pensador de Danzig. Podríamos preguntarnos hasta qué punto Schopenhauer comparte el ideal objetivista atribuido a la ciencia hoy día, en la que desde Platón, llegando hasta Popper, una larga tradición ha venido cifrando la noble finalidad de esclarecer la verdad pura. Seguramente, para Schopenhauer la ciencia perseguiría como tal una simple verdad lógica, propia del intelecto sometido a aquel principio de razón suficiente que según el regiría las representaciones, y por tanto propia del plano individual y empírico; en tanto que los objetos percibidos afectan a nuestra voluntad, mantenemos una relación interesada con ella, siendo así que la verdad objetiva codiciada por el científico la obtenemos observando las relaciones que mantienen los objetos 
entre sí, pero que indirectamente termina por relacionarse con nuestra voluntad. Así pues, creemos que la ciencia se arrogaría un carácter marcadamente pragmático y utilitarista según Schopenhauer. Como contrapunto a esto, el «eidos» qua objetivación de la voluntad, contemplada sin embargo por un sujeto que logra aplacar las necesidades de la voluntad y las funcionalidades que ella busca en los fenómenos concretos y plurales, nos pone en la pista de una muy diversa acepción de «verdad», la «verdad estética» o «verdad metaempírica», dado que apunta a lo eterno e incorruptible y reproduce en gran medida, como veremos, ese fondo platónico. Donde el científico encuentra la verdad lógica que abstrae nominalistamente tras haber experimentado con los fenómenos, el genio y el artista captan intuitivamente la verdad estética (el eidos); ambos, pues, son modos cognoscitivos, puesto que invocan el plano representacional, aunque cada uno ocupe un nivel y género muy distinto.

El hacer artístico (poiesis) constituye un tipo de sabiduría privilegiado al llevar implícita la intuición artística eidética (o transeidética en la música), un tipo de sabiduría que nos purifica y nos alegra la existencia como si descansáramos en un oasis letificante en medio del tedio y la comezón del deseo. En sintonía con la sensibilidad griega, Schopenhauer considera el arte una feliz catarsis, poniendo la música en lo más alto. No obstante, esta poiesis del arte habría de ser complementada con la sabiduría moral y ascética, ganando para sí la praxis y la completa liberación que conlleva neutralizar la voluntad de vivir. En el arte negamos temporalmente esta voluntad de vivir, ya que volvemos a la carga afirmándola toda vez que nos vemos apremiados por nuestros menesteres cotidianos (el genio aún sigue participando de ellos). Pero cuando decidimos llevar una vida santa y ascética, alcanzamos por fin ese alejamiento del dolor, la noluntad, acercándonos a una concepción de la felicidad más bien estoica, proclive a la serenidad, y no ya tan acorde con el goce que conseguimos en la experiencia artística. Con el arte descansamos del tráfago de una vida incesantemente abocada a la lucha y la tribulación; con la ética y la ascética, dejamos de luchar y atribularnos para redimirnos del sufrimiento, haciendo de esta redención un modus vivendi. Lo más logrado, pues, que cabría concebir humanamente hablando sería un individuo esteta, asceta y compasivo, que agolpara en su sola persona la genialidad para crear obras artísticas y la perspicacia para procurar llevar y hacer llevar una vida lo menos miserable posible: he aquí por fin aparejados goce estético y salvación ética. 
José Antonio Cabrera es Doctor en Filosofía por la Universidad de Sevilla.

Líneas principales de investigación:

Gnoseología, Historia de la Filosofía, Antropología Filosófica.

Publicaciones recientes:

- «La clave del mundo: corporalidad y autognosis en Arthur Schopenhauer». Daimon. Revista Internacional de Filosofía. 2016. Núm. Suplemento 5. Pag. 371-380.

- «Schopenhauer, Wagner y la intuición musical». Schopenhaueriana. Revista de Estudios sobre Schopenhauer en Español. 2016. Núm. 1. Pag. 123-137.

- «El trasfondo psicologista en la teoría schopenhaueriana de la percepción». Estudios de Filosofía. 2015. Núm. 52. Pag. 95-110.

Dirección postal:

Universidad de Sevilla

C/ Camilo José Cela, s/n. 41018 - Sevilla.

E-mail: jcabrera7@us.es 
